\title{
THE OUTBREAK OF COVID-19 — MEDICAL LEADERSHIP CHALLENGE
}

\author{
Eldad Katorza ${ }^{1,2,3} \odot$, Arnon Afek ${ }^{1,3} \odot$, Elon Glassberg ${ }^{4,5} \odot$, Elhanan Bar-0 ${ }^{3,6} \odot$, Yitshak Kreiss ${ }^{1,3} \odot$ \\ ${ }^{1}$ Medical Management, Sheba Medical Center, Tel-Hashomer, Ramat-Gan, Israel \\ ${ }^{2}$ Department of Obstetrics and Gynecology, Sheba Medical Center, Tel-Hashomer, Ramat-Gan, Israel \\ ${ }^{3}$ Sackler School of Medicine, Tel-Aviv University, Tel Aviv, Israel \\ ${ }^{4}$ Israel Defense Forces Medical Corpus \\ ${ }^{5}$ Bar-Ilan University, Faculty of Medicine, Safed, Israel \\ ${ }^{6}$ Center of disaster Medicine, Sheba Medical Center, Tel-Hashomer, Ramat-Gan, Israel
}

KEY WORDS: COVID-19, outbreak, medical, leadership

Disaster Emerg Med J 2020; 5(2)

The Corona Virus Disease 2019 (COVID-19) outbreak surprised humanity with its scale and speed. Starting in Wuhan, the capital city of Central China's Hubei province, it rapidly spreads to East Asia, Iran, Europe and the United States of America [1]. So far, only a few countries on earth have not yet been affected by the pandemic. Dealing with an emerging new disease is particularly challenging and requires complex decision making and leadership, of both medical leaders and statesmen. Factors such as logistical and technological capabilities, medical staff training level, operational flexibility and leadership, will determine how well healthcare organizations (and nations) will cope with the challenge. In this paper, we present six major leadership dilemmas and possible solutions, in an attempt to provide tools that will assist in confronting such an extreme event:

\section{WHAT IS THE PRICE WE ARE WILLING TO PAY FOR SAVING LIVES?}

\section{Containment and mitigation policies:}

Countries of the world can be schematically divided into two main groups according to their choice of how to tackle this outbreak: those who acted resolutely to quickly control the epidemic from the time of its emergence (Singapore, Taiwan, Japan, and South Korea) and those who delayed until the scale and the severity of the outbreak were apparent before taking the appropriate steps (such as Italy, Iran, and Spain). It was soon found that morbidity and mortality rates were significantly lower in countries that adopted strict citizen isolation and closure policies, as well as, massive population testing [2]. Each country has different cultural, social, geopolitical, economic and military characteristics that affect its ability to function in health crises. The structure of the healthcare system, the form of insurance coverage and the regulation of the system also have a decisive influence on the ability of that country to cope with such crises. When confronted with an outbreak, determination, decisiveness and speed of actions by the medical leaders will not only save lives but also reduce the implications of associated effects.

\section{WHAT IS THE STATE'S COMMITMENT TO ITS CITIZENS AND SHOULD IT BE MAINTAINED AT ALL COSTS?}

\section{The Diamond Princess dilemma:}

Six days after an 80-year-old guest disembarked from this cruise ship on $1^{\text {st }}$ February 2020, he visited 
a local Hong Kong hospital, where he later diagnosed positive for COVID-19 [ 3]. By the end of February, more than 600 out of the 3.711 passengers and crew were infected with the virus [4]. Among the passengers were 3 Israeli passengers who tested positive for COVID-19 and were sent to a local hospital in Japan for further treatment. On the $17^{\text {th }}$ of February, the Israeli government followed several other nations and decided to bring home the other 10 Israeli passengers from quarantined on the ship. On the $20^{\text {th }}$ of February, they were transported back to Israel and hospitalized in isolated conditions for further examination and treatment. This decision was criticized by the media and the public because, until then, there were no verified COVID-19 cases in Israel. The arrival of these citizens carried the risk of bringing the virus into the country. The Israeli government (and the medical committee) decided that the state's moral commitment to care for its' citizens, overcame the fear and the danger surrounding this decision. The bad taste of possible rejection the return of these citizens would have remained long after the end of the pandemic.

\section{CONTINUE TO PROVIDE ESSENTIAL AND LIFE-SAVING MEDICAL SERVICES, OR REDIRECT ALL RESOURCES TO DEAL WITH THE CURRENT CRISIS?}

Sheba Medical Center (SMC) is a leading medical center in Israel with cutting edge clinical and technological capabilities. The Israeli Ministry of Health $(\mathrm{MoH})$ elected SMC for the management and treatment of the first corona patients, include the Israeli returned Diamond Princess' passengers. This, in turn, required both recruiting the most suitable and skilled teams and selecting the most appropriate site (and facility) within the hospital for the hospitalization and treatment of the COVID-19 positive patients. At that time, there was uncertainty as to the optimal model of treatment. It was clear to us that we are committed to continuing to provide essential and life-saving medical services in order to prevent significant harm to citizens' health. Thus, we chose to set up a separate site for the COVID-19 Patients to minimize any impairment of the necessary medical function at the main hospital. Several considerations were taken into account when selecting the site for treatment of these patients: isolation, accessibility, the safety of the medical teams and other hospitalized patients, minimizing disruption of the regular medical activities and lifesaving procedures that are performed at the hospital, the distance from population centers while still relying on some of the capabilities of the hospital. The quickest and most convenient way would have been to assign a hospital ward and tailor it to care for these patients, drawing on existing organic staff and facilities. In order to minimize the danger of exposing patients and staff to the virus and the risk of harming the hospital's essential routine activities, we chose a dedicated, separated facility. This allowed us to deploy and introduce technologies that are not routinely used in the hospital such as telemedicine for in house medical care, wireless sensors, robots etc. Additionally, an institutional multidisciplinary team was formed including medical directors and experts' physicians in the fields of disaster medicine, internal medicine and infectious diseases, public health specialists, technology and logistics personnel, psychologists, spokesperson-public relations and ethics-law experts. Simulators were used to train the teams, familiarize them with the disease characteristics and the new tools. The decision where to place the site to treat the COVID-19 patients depends on the variety of factors and should be considered according to the local conditions. Medical managers need to be involved and lead this important decision that affects the functioning and availability of medical services and the safety of people are hospitalized and medical staff.

\section{TEAM ENDURANCE — THE GREATEST CHALLENGE:}

\section{The "big picture" dilemma [5] — How much it should be shared with the team?}

Fear of the unknown is an integral part of such a crisis for both the civilians and the medical teams, concerned is not only for their safety but for their families and patients. As always in crisis, in order to minimalize concerns, maintain motivation and morale and avoid dissemination of false rumours, transparency and openness are required. Along with psychological support, this will promote earning the trust from both the employees and the general public. 


\section{COMPLEX DECISION MAKING — ETHICAL AND MORAL DILEMMAS:}

\section{What if we must choose who gets cared for (and who does not)?}

Under such extreme situations, difficult ethical dilemmas may emerge, and clear and uniform policy is required, to guide providers confronted with difficult questions. Preparation of special ethics committees are required, involving ethics experts and senior medical leaders do develop limited resource allocation policies such as protective equipment, expensive drugs and allocation of life-saving technologies such as respirators. These impossible decisions should not be left in the hands of the medical teams but should be pre-determined and clearly communicated to them. Quick decision-making based on situational analysis, knowledge and experience is expected of the medical leadership in extremely difficult situations. Being late and hesitant in decision making can have devastating results.

\section{COLLABORATION AS A STRATEGY:}

\section{How important are communication and collaboration?}

One of the features of a modern economy is competition and differentiation. In situations when a common threat appears, cooperation in the form of sharing knowledge and experience are required, on both, national and international level. The experience gained by countries where the virus struck earlier could be lifesaving for countries where no mass infection has yet occurred. In crisis situations, working alone is simply not an option. Collaboration in the form of resource and knowledge sharing and transfer of equipment between hospitals and states is difficult in times of crisis, with everyone taking care of themselves, but this is true leadership and should be sought after.

While pandemic events are not often, they result in significant morbidity, mortality, disruption of life and have a major global economic effect. Medical teams and medical directors should be appropriately prepared and trained to face such a challenge. This could allow for controlling such events in the earliest stages possible. Leadership are further challenged between the epidemics, as they are charged with having to influence policy makers to prioritize readiness and create collaborations.

It is not easy to be a leader, but it is the duty of the medical leaders who emerge during a crisis. The way in which we handle medical leadership dilemmas may be of value for the oncoming challenges.

Funding: No funding was received.

Conflict of interest: The authors declare that they have no conflict of interest.

Acknowledgements: None.

\section{REFERENCES:}

1. https://www.who.int/docs/default-source/coronaviruse/situation-reports/20200226 sitrep-37-covid-19.pdf?sfvrsn=6126c0a4_2.

2. Wu Z, McGoogan JM. Characteristics of and Important Lessons From the Coronavirus Disease 2019 (COVID-19) Outbreak in China: Summary of a Report of 72314 Cases From the Chinese Center for Disease Control and Prevention. JAMA. 2020 [Epub ahead of print], doi: 10.1001/jama.2020.2648, indexed in Pubmed: 32091533.

3. Updates on Diamond Princess. Retrieved 11 February. ; 2020: 2020.

4. Kang Y. Investigation on COVID-19 Infection Cases in Korea. , doi: 10.21203/rs.3.rs-18483/v1.

5. Hershkovich O, Gilad D, Zimlichman E, et al. Effective medical leadership in times of emergency: a perspective. Disaster Mil Med. 2016; 2: 4, doi: 10.1186/s40696-016-0013-8, indexed in Pubmed: 28265438. 